\title{
Comparison of Classical Open Appendectomy, Small Incision Appendectomy and Laparoscopic Appendectomy in Children with Uncomplicated Acute Appendicitis
}

\author{
Sheikh Imran Gul', Asim Rafiq Laharwal' ${ }^{2}$, Ajaz Ahmad Wani', Arshad Rashid ${ }^{2}$, \\ ${ }^{1}$ Surgeon Specialist, Health Services Kashmir, (Current Affiliation), Post-graduate Scholar \& Registrar, \\ Department of General Surgery, GMC Srinaga, (At the time of study), ${ }^{2}$ Lecturer, Department of Surgery, \\ Government Medical College \& Associated Hospitals, Srinagar
}

\begin{abstract}
Background: The surgical anatomy of appendix coupled with a lax abdominal wall in children creates a possibility of accomplishing an appendectomy using a small incision. The aim of the present study was to compare the outcomes of classical grid iron, small incision and laparoscopic appendectomy in children with uncomplicated acute appendicitis.
\end{abstract}

Method: A prospective comparative study was undertaken at a tertiary care hospital, where patients who underwent either open (classical or small incision) or laparoscopic appendicectomy were studied and compared for various intraoperative and postoperative parameters. The subjects selected for study were children in the age group of $4-14$ years of age, and were diagnosed as having simple acute appendicitis.

Results: Out of a total of 201 patients included in the study; 78 underwent appendectomy by classical Grid iron incision, 62 by small incision and 67 by a conventional laparoscopic method. The baseline parameters were similar in all the three groups. The mean operative time was significantly lower in small incision group. There was no intra-operative complication noticed in any of the groups. Conversions were significantly higher in the small incision group as compared to classical grid iron and laparoscopic approach. The mean pain scores (visual analogue scale) were significantly decreased in the laparoscopic group. The mean hospital stay and return to activities of daily life was significantly increased in the classical grid iron group.

Conclusion: Laparoscopic approach for appendectomy seems to be a clear winner in uncomplicated paediatric appendicitis, but small incision approach provides an acceptable alternative, as compared to the standard grid iron incision.

Key Words: Appendectomy; Laparoscopic; Grid Iron; Small Incision; Children.

\section{Introduction}

Appendectomy is a very common general surgical procedure ${ }^{1,3}$. Like every other procedure, minimal access surgery has made its mark in appendectomy as well. As

\footnotetext{
Corresponding Author:

Dr Asim R Laharwal

Department of Surgery, Government Medical College

\& Associated Hospitals, Srinagar - 190010.

E mail :asimlaharwal@gmail.com; Phone:

$+919906966113$
}

far as complicated appendicitis is concerned the choice of surgery whether open or laparoscopic is equivocal, but far too many studies favour laparoscopic appendectomy in simple acute appendicitis ${ }^{2,4}$. It is a less spoken fact that as time has passed even open surgeons have evolved and prefer making small incisions compared to erstwhile bigger ones. Small incisions though sometimes criticised, more so in emergency cases, are supported in a surgery like appendectomy, owing to the mobile nature of caecum to which the appendix is attached. The aim of the present study was to compare the outcomes of classical grid iron, small incision and laparoscopic 
appendectomy in children with uncomplicated acute appendicitis.

\section{Materials and method}

A prospective comparative study was undertaken at a tertiary care hospital, where patients who underwent either open (classical or small incision) or laparoscopic appendicectomy were studied and compared for various intraoperative and postoperative parameters. The data was compared with retrospective data of children operated over a previous year by normal McBurney's grid iron incision. The subjects selected for study were children in the age group of $4-14$ years of age, and were diagnosed as having simple acute appendicitis. The children having Alvorado score more than 7 and/ or inflamed appendix on high frequency ultrasound were operated upon. Patients with complicated appendicitis or those who refused to participate in the study were excluded from the study. Children with simple acute appendicitis who were admitted during the day in emergency underwent laparoscopic appendicectomy in general elective theatres. Children who were admitted in the evening underwent open appendicectomy as laparoscopic facilities were not available in our hospital in the emergency department.

The laparoscopic appendicectomy was done using the standard procedure. The standard grid iron approach was employed for the grid iron group. The small incision open procedure was done using a mini horizontal incision ( less than $3 \mathrm{~cm}$ ) at Mcburney's point, incising the skin, subcutaneous tissue and external oblique aponeurosis in the same line as that of the incision. The internal oblique and transversus abdominis were split and the peritoneum opened in the same line as that of the incision. The appendix was located with an index finger inserted through the incision into the abdominal cavity and once located was brought out using counterpressure with the palm of the other hand over the abdominal wall. Alternately, the gut loops were set aside using a ribbon guaze and a narrow blade retractor. Once visualised the appendix was brought out of the incision using a babcock. The rest of the procedure followed the standard steps. Conversions if done, were from grid iron to Rutherford Morrison in the grid iron incision group. Small incision patient needed a conversion to right lower transverse incision as lateral extension of the incision was not possible for the fear of injuring the iliohypogastric and ilioinguinal nerves.

An approval from the institutional ethical committee was obtained for the purpose of this study. A written and informed consent was taken from the patients' first degree relatives for publication and analysis of their data after explaining to them the protocol of the study in their own language. The data thus collected was compiled and analyzed using SPSS version 21 for Mac (IBM Corporation, 2012). To calculate the P-value, Fisher's exact test and Pearson's chi-square test were applied to compare the frequencies for categorical parameters, and the unpaired t-test was used to compare the means (2-tailed) among continuous variables. The results were calculated on $95 \%$ confidence interval. A P-value $<0.05$ was considered significant.

\section{Results}

Out of a total of 201 patients included in the study; 78 underwent appendectomy by classical Grid iron incision, 62 by small incision and 67 by a conventional laparoscopic method. The baseline parameters were similar in all the three groups (Table 1). The mean operative time was significantly lower in small incision group (21.60 \pm 3.71 minutes) as compared to classical grid iron (29.88 \pm 5.74 minutes) and laparoscopic group $(46.75 \pm 7.64$ minutes, $\mathrm{p}<0.0001)$. There was no intraoperative complication noticed in any of the groups. The mean pain scores (visual analogue scale) were significantly decreased in the laparoscopic group (5.88 $\pm 0.73)$ as compared to small incision $(6.37 \pm 0.61)$ and classical grid iron approach $(7.23 \pm 0.58, \mathrm{p}<0.0001)$.

Table 1: Baseline parameters of the three groups.

\begin{tabular}{|l|l|l|l|l|}
\hline PARAMETER & Grid Iron $(\mathbf{n}=\mathbf{7 8})$ & Small Incision $(\mathbf{n}=\mathbf{6 2})$ & Laparoscopic $(\mathbf{n}=\mathbf{6 7})$ & P VALUE \\
\hline Age (years) & $8.19 \pm 3.15$ & $8.35 \pm 3.04$ & $8.37 \pm 3.05$ & 0.5124 \\
\hline Sex (M: F) & $36: 42$ & $29: 33$ & $32: 35$ & 0.6167 \\
\hline Rural: Urban & $41: 37$ & $39: 23$ & $38: 29$ & 0.1736 \\
\hline Mean Alvarado Score & $8.27 \pm 0.16$ & $8.12 \pm 0.09$ & $8.23 \pm 0.21$ & 0.2631 \\
\hline
\end{tabular}


Conversions were significantly higher in the small incision group $[12(19.35 \%)]$ as compared to classical grid iron [11 (14.10\%)] and laparoscopic approach [6 (8.95\%), $\mathrm{p}<0.0001]$. Wound infection was significantly more in the classical grid iron approach [3 (3.84\%)] as compared to small incision [2 (3.22\%)] or laparoscopic method [1 (1.49\%), p < 0.0001]. The wound infection was seen more often in patients converted to Rutherford Morrison incision [2 out of 12 (16.67\%)] from classical grid iron incision [1 out of 66 $(1.51 \%), \mathrm{p}<0.0001]$. The mean hospital stay was not significantly different in the laparoscopic group (1.12 \pm 0.21 days $)$ and small incision group $(1.26 \pm 0.31$ days, $\mathrm{p}=0.5138$ ) but it was significantly increased in the classical grid iron approach $(2.11 \pm 0.58$ days, $\mathrm{p}<$ 0.0001). Likewise, patients undergoing laparoscopic appendectomy resumed their activities of daily life earlier as compared to small incision group, but it was not statistically significant $(7.36 \pm 2.27$ versus $8.12 \pm$ 2.36 days, $\mathrm{p}=0.6259$ ). However, when compared to patients undergoing appendectomy by classical grid iron method, it was statistically significant $(12.37 \pm 3.28$ days, $\mathrm{p}<0.0001)$.

\section{Discussion}

Appendectomy is considered a basic and one of the most common surgical procedures performed the world over. Appendicitis is very common in the paediatric age group. The peculiar surgical anatomy of appendix coupled with a lax abdominal wall in children poses a unique possibility of accomplishing an appendectomy using a small incision. However after the advent of laparoscopy probably the need for modifying open approach was not felt as much and thus we have very sparse literature on modified approaches for appendectomy. Though laparoscopy is becoming common in the developing world, still there are far too little hospitals with laparoscopic setup and that too limited to elective units.

In adult patients, large multicenter studies have shown that irrespective of the severity of appendicitis, laparoscopic appendectomy may be the favoured approach ${ }^{1}$. As far as children are considered varied opinions come to the front with an open dividing line among surgeons regarding safety of laparoscopic appendectomy as compared to open appendectomy in complicated appendicitis. Whereas one group advocates advantages with respect to hospital stay and postoperative morbidity with laparoscopic approach in children with uncomplicated appendicitis only, with a higher rate of intraabdominal abscess formation with laparoscopic appendectomy in complicated appendicitis. Others believe no such increased risk of intrabdominal abscesses exists in children with complicated appendicitis with laparoscopic approach ${ }^{2,5}$.

Some authors are of the opinion that the differences in post-operative complications in paediatric patients may be due differences in skill levels of operating laparoscopic surgeons $s^{6,8}$. By and large studies favour laparoscopic approach in the paediatric group as it provides for reduced post-operative morbidity ${ }^{7}$. However, increased operative time and elevated costs have also been implicated as short comings of laparoscopic appendectomy in paediatric patients ${ }^{9}$. However, the overall trend is favouring laparoscopic appendectomy in appendicitis in children, whether complicated or uncomplicated ${ }^{10,11}$. In order to minimize the post operative morbidity of open approach surgeons in the developing world have at times tried small incisions for appendectomy ${ }^{12}$.

In the present study it was observed that the operative time was the lowest in the small incision group, probably due to the small incison that took lesser time for opening and closure. Though laparoscopy fared marginally better than small incision approach in terms of hospital stay, return to activities of daily life and wound infection but the small incision approach scored significantly better than the classic grid iron approach in terms of these parameters. The major causes of postoperative pain are the length of fascial incision and the intra-operative stretching of the wound site $^{13}$. Thus it is logical to expect that the pain scores would be lower in laparoscopic and the small incision approach as compared to the classical grid iron method, which was indeed the case in our study.

The present study has some potential limitations. This was not a randomized controlled trial as the decision to perform appendectomy by laparoscopic approach depended on the time of presentation of the patient, as laparoscopy was only available during the day time. However, the patients in the small incision and classical grid iron group were randomized by flipping a coin. We have also not been able to do a cost benefit analysis of the different approaches. It was not done because we were not having a dedicated laparoscopic unit for this study and the same instruments were being used to perform other laparoscopic surgeries as well and cost assessment of wear and tear of the reusable instruments and other 
materials like insufflation agents was difficult.

\section{Conclusion}

Though laparoscopic approach for appendectomy seems to be a clear winner in uncomplicated paediatric appendicitis, this approach is not easily available at all the centers in the developing world. So till the laparoscopic approach becomes a common place in the developing world emergency surgical units, it might be feasible to use a small incision approach with acceptable levels of post-operative morbidity, as compared to the standard grid iron incision. The small incision approach provides all the benefits of minimal access surgery.

Source of Conflict: All the authors declare that there are no potential conflicts of interests or any financial interests with the commercial identities mentioned in the paper.

\section{Source of Funding: None}

\section{References}

1. Tiwari MM, Reynoso JF, Tsang AW, Oleynikov D. Comparison of outcomes of laparoscopic and open appendectomy in management of uncomplicated and complicated appendicitis. Ann Surg. 2011;254(6):927-32.

2. Markar SR, Blackburn S, Cobb R, Karthikesalingam A, Evans J, Kinross J, Faiz O. Laparoscopic versus open appendectomy for complicated and uncomplicated appendicitis in children. $J$ Gastrointest Surg. 2012;16(10):1993-2004.

3. Oka T, Kurkchubasche AG, Bussey JG, Wesselhoeft CW Jr, Tracy TF Jr, Luks FI. Open and laparoscopic appendectomy are equally safe and acceptable in children. Surg Endosc. 2004;18(2):242-5.

4. Nataraja RM, Teague WJ, Galea J, Moore L, Haddad MJ, Tsang T, Khurana S, Clarke SA. Comparison of intraabdominal abscess formation after laparoscopic and open appendicectomies in children. $J$ Pediatr Surg. 2012;47(2):317-21.

5. Masoomi H, Mills S, Dolich MO, Ketana N, Carmichael JC, Nguyen NT, Stamos MJ.
Comparison of outcomes of laparoscopic versus open appendectomy in children: data from the Nationwide Inpatient Sample (NIS), 2006-2008. World J Surg. 2012;36(3):573-8.

6. Oyetunji TA, Nwomeh BC, Ong'uti SK, Gonzalez DO, Cornwell EE, Fullum TM. Laparoscopic appendectomy in children with complicated appendicitis: ethnic disparity amid changing trend. J Surg Res. 2011;170(1):e99-103.

7. Aziz O, Athanasiou T, Tekkis PP, Purkayastha S, Haddow J, Malinovski V, Paraskeva P, Darzi A. Laparoscopic versus open appendectomy in children: a meta-analysis. Ann Surg. 2006;243(1):17-27.

8. Esposito C, Calvo AI, Castagnetti M, Alicchio F, Suarez C, Giurin I, Settimi A. Open versus laparoscopic appendectomy in the pediatric population: a literature review and analysis of complications. J Laparoendosc Adv Surg Tech A. 2012;22(8):834-9.

9. Blakely ML, Spurbeck WW, Laksman S, Hanna K, Schropp KP, Lobe TE. Laparoscopic appendectomy in children. Semin Laparosc Surg. 1998;5(1):14-8.

10. Zwintscher NP, Johnson EK, Martin MJ, Newton CR.Laparoscopy utilization and outcomes for appendicitis in small children. J Pediatr Surg. 2013;48(9):1941-5.

11. Wang X, Zhang W, Yang X, Shao J, Zhou X, Yuan J. Complicated appendicitis in children: is laparoscopic appendectomy appropriate? A comparative study with the open appendectomy-our experience. J Pediatr Surg. 2009;44(10):19247.

12. Malik AH, Wani RA, Saima BD, Wani MY. Small lateral access--an alternative approach to appendicitis in paediatric patients: a randomised controlled trial. Int J Surg. 2007;5(4):234-8.

13. Rashid A, Nazir S, Kakroo SM, Chalkoo MA, Razvi SA, Wani AA. Laparoscopic interval appendectomy versus open interval appendectomy: A prospective randomized controlled trial. Surg Laparosc Endosc Percutan Tech. 2013;23(1):93-96 